\title{
ELECTROCARDIOGRAPHIC PATTERNS IN SLIGHT CORONARY ATTACKS
}

\author{
BY \\ CORNELIO PAPP AND K. SHIRLEY SMITH \\ From the Cardiac Department, Charing Cross Hospital
}

Received April 20, 1950

The seriousness of cardiac infarction can be assessed on clinical grounds. Prolonged pain refractory to morphia, severe shock with fall of blood pressure to dangerous levels, and the early onset of cardiac failure are unequivocal signs of a severe attack. In many patients regarded as suffering from cardiac infarction there are none of these signs, and the diagnosis is based on coronary pain accompanied by electrocardiographic changes of acute myocardial ischæmia. Were it not for the persistent electrocardiographic signs such attacks would be more suggestive of prolonged bouts of angina at rest than cardiac infarction proper. The clinical term "slight coronary attack" applied to this condition seems thus appropriate, for the symptoms are slight and the name disregards the problematic existence of actual thrombosis and myocardial necrosis. Slight coronary attack implies cardiac pain for half an hour or more, arising at rest and not relieved by trinitrin, always accompanied by persistent electrocardiographic signs of myocardial ischæmia but not by the clinical and laboratory signs of extensive myocardial necrosis (Papp, 1949)

Similar conditions have been variously described. "Coronary insufficiency without occlusion" is the term used by Master (1946) for a condition more severe than angina of effort but lighter than acute myocardial infarction-for the latter he proposes the name " acute coronary insufficiency with acute occlusion". He lists a great number of exciting causes restricting coronary blood flow and responsible for the attack. But these have only exceptionally played any part in our series, in which the attacks were as sudden and devoid of cause as in the classical acute coronary occlusion. " Coronary failure " is the name given by Freedberg, Blumgart, Zoll and Schlesinger (1948) for the " clinical syndrome intermediate between angina pectoris and acute myocardial infarction ". This syndrome is of wide range and comprises some of our cases. However, in coronary failure the electrocardiographic changes are slight or absent, except in the more severe cases where they may persist for hours and then revert to normal. This was not so in the majority of our series where a diagnosis of cardiac infarction was made on the basis of persistent electrocardiographic changes showing the initial signs of acute myocardial ischæmia with subsequent serial changes typical of such lesions for weeks or months after the acute attack.

The purpose of the present investigation is, first, to determine the incidence of slight coronary attacks and how far there is an agreement between the slight clinical and electrocardiographic features ; secondly, to investigate the prognosis of the attack and the incidence of the early complications, and thirdly, to draw conclusions regarding treatment.

\section{MATERIAL AND Method of Investigation}

A clinical analysis has been made of one hundred and nine consecutive patients with a diagnosis of cardiac infarction. They consisted of 63 hospital in-patients, 24 patients seen in consultant practice, and 22 seen in general practice. No case first seen more than a fortnight after the acute 
attack was included, nor any in whom there were less than two confirmatory electrocardiograms. Among these 109 cases there were 33-little less than one-third-in whom no shock or cardiac failure followed the attack. These were regarded as having had slight coronary attacks ; 12 were hospital in-patients, 12 were seen in consultant practice, and 9 in general practice. Thus patients with slight coronary attacks were almost twice as frequent outside as inside hospitals. Ages ranged from 42 to 73 years, with the greatest incidence between 50 and 69 (24 patients); two were over 70. The proportion of men to women was three to one (Table I).

TABLE I

Age and Sex in 33 Patients With Slight Coronary Attacks

\begin{tabular}{c|c|c|c|c|c}
\hline Age : & $40-49$ & $50-59$ & $60-69$ & $70-73$ & Total \\
\hline Males : & 7 & 9 & 7 & 2 & 25 \\
Females : & - & 2 & 6 & - & 8 \\
\hline
\end{tabular}

Proportion of men to women $=3: 1$

\section{Clinical Analysis of Slight Coronary Attacks}

Pre-existing conditions. Angina of effort was complained of in 17 ; it had existed for more than two months in 12, and for less than two weeks in 5, where it followed the acute attack. In addition, 6 further patients developed angina after their coronary attacks ; this brings the total number of patients suffering from angina to 23 . Coronary thrombosis had been diagnosed in five previously ; in three, who were seen during these attacks, they were slight. There were 10 hypertensives, 4 diabetics, and 3 obese patients in the series ; obesity, diabetes, and angina of effort coexisted in three. Two were chain-smokers and one had intermittent claudication; in only two had there been no previous symptoms or associated disorders.

Pain. Prolonged attacks suggesting coronary occlusion were present in 27 cases. In these, the pain lasted from one to twelve hours. In longer lasting attacks, the pain was intermittent ; it was difficult to form an accurate judgement of the intensity of pain, but the fact that only half of the patients with attacks longer than one hour required morphia is inconsistent with extreme pain. With one exception (Case 9, Fig. 9) a single injection of morphia (gr. 1/4 to 1/3) suppressed the pain. The onset of pain was sudden and mostly occurred at night during sleep ; in four it started while the patient was walking. Major physical effort could be held responsible only in two ; in Case 9, the pain started while the patient was dancing after a heavy meal ; in Case 6 (Fig. 6), while he was cranking a car. In Case 22 it began under spinal anæsthesia during investigation for intermittent claudication. The spread and quality of pain were characteristic of cardiac infarction. Anginal pain frequently recurred during the period of observation ; it rarely required injection of morphia and was usually abolished by trinitrin or pethidine tablets. In six patients who had no longer lasting bouts of pain, the attacks were those of angina of effort or at rest and none of them required morphia ; in these the diagnosis was based on the electrocardiogram only. Severe angina of effort following the acute attack, not the attack itself, was the reason why medical help was sought in three patients.

Fall of blood pressure was irrelevant in most. The systolic blood pressure was never less than 100 and only in five was it from 100 to 110 for a short time. The diastolic blood pressure was well in proportion with the systolic, and the pulse pressure never fell below 30 .

Pulse rate was normal and the rhythm regular in all during the period following the attack. Two patients, while having the attack, had regular ectopic tachycardia ; Case 9, with a rate of 160 , Case 21, at a rate of 176 .

Pyrexia was found in five. In Case 14 it lasted for five days ; in the others, one to three days, with a maximum of $101^{\circ} \mathrm{F}$. 
White cell count was raised to 9500 in Case 13 . In seven other patients, seen sufficiently soon after the attack, it was normal. Blood sedimentation rate was raised in five instances to a maximum of 32 in the hour, and was normal in seven.

Course. The clinical course was uneventful and all the patients recovered from the acute attack. There were no pulmonary or embolic complications during the two-months period of close observation, but Case 9, eight months later, had a cerebral embolism from which he recovered. Cardiac enlargement with evidence of slight failure was seen in Case 15, an obese diabetic, two years after he had the first slight coronary attack. In all the others the heart size was normal on radioscopy except for a few patients with slight left ventricular hypertrophy consistent with coexistent hypertension. Angina of effort in more or less severe degree or short attacks of angina at rest were frequent features ; they were present in 23 out of 33 patients during the period of observation lasting from two months to over three years.

\section{EleCtrocardiographic Features}

Electrocardiograms recorded following 35 slight coronary attacks (Cases 8 and 15 were seen in two attacks, both slight) showed the following patterns of myocardial ischæmia (Table II).

TABLE II

Electrocardiographic Analysis of 35 Slight Coronary Attacks

\begin{tabular}{l|c|c|c|c|c|c}
\hline & $\begin{array}{c}(17) \\
\text { Ant. } \\
\text { septal }\end{array}$ & $\begin{array}{c}\text { (7) } \\
\text { Ant. } \\
\text { lateral }\end{array}$ & $\begin{array}{c}(2) \\
\text { Ant. } \\
\text { apical }\end{array}$ & $\begin{array}{c}(6) \\
\text { Post. }\end{array}$ & $\begin{array}{c}(3) \\
\text { Post. } \\
\text { lateral }\end{array}$ & $\begin{array}{c}(35) \\
\text { Total }\end{array}$ \\
\hline R small or abs. & 3 & - & - & - & - & 3 \\
Q present & 3 & 1 & $\frac{1}{2}$ & 2 & - & 7 \\
EC restored & 7 & 4 & $\frac{1}{1}$ & 3 & $\frac{1}{1}$ & 14 \\
EC improved \\
EC unchanged & 9 & 1 & 1 & 1 & 1 & 1 \\
EC worse & - & - & - & - & 1 \\
\hline
\end{tabular}

*Varied from normal to abnormal.

Anteroseptal, with changes in leads $V_{1}$ to $V_{6}$ with main changes in leads $V_{2}$ to $V_{3}$, in 17 instances (Fig 1, 2, 3, 5 and 7).

Anterolateral, with changes in leads $V_{4}$ to $V_{6}$, in 7 instances (Fig. 4).

Antero-apical, with changes in $\mathrm{V}_{4}$, in 2 instances (Fig 6 and 8).

Posterior, with changes in leads II, III and AVF, 6 instances (Fig. 10, 11 and 12).

Posterolateral with changes in leads III, AVF, $V_{5}$ to $V_{7}$, in 3 instances (Fig. 9).

According to the position of the heart, the anteroseptal and anterolateral changes were carried into leads AVL and I, rarely into AVF. On the whole, the unipolar extremity leads were of little help in the diagnosis of these patterns and could be dispensed with.

Abnormality of $\mathbf{R}-\mathrm{T}$ or $\mathrm{T}$ wave patterns were prominent in all records and consisted of high take-off, coving of $R-T$ and deep $T$ inversion in one or more leads. When these changes were conspicuous in $V_{2}$ to $V_{4}$, as they always are in anteroseptal ischæmia (Fig 1,2,5 and 7), they faintly recalled the ones found in right ventricular hypertrophy and in localized pericarditis. There was no reason to assume that either of these conditions existed in our patients, since no case of pulmonary infarction accurred in our series nor was pericardial rub ever heard. On the other hand, there was great similarity between our records of anteroseptal ischæmia and those of Brock and Campbell (1950) found during the healing stage of right ventricular wounds in patients operated on for pulmonary stenosis. Current of injury was recorded once (Case 3, Fig. 3). The $R$ wave was 


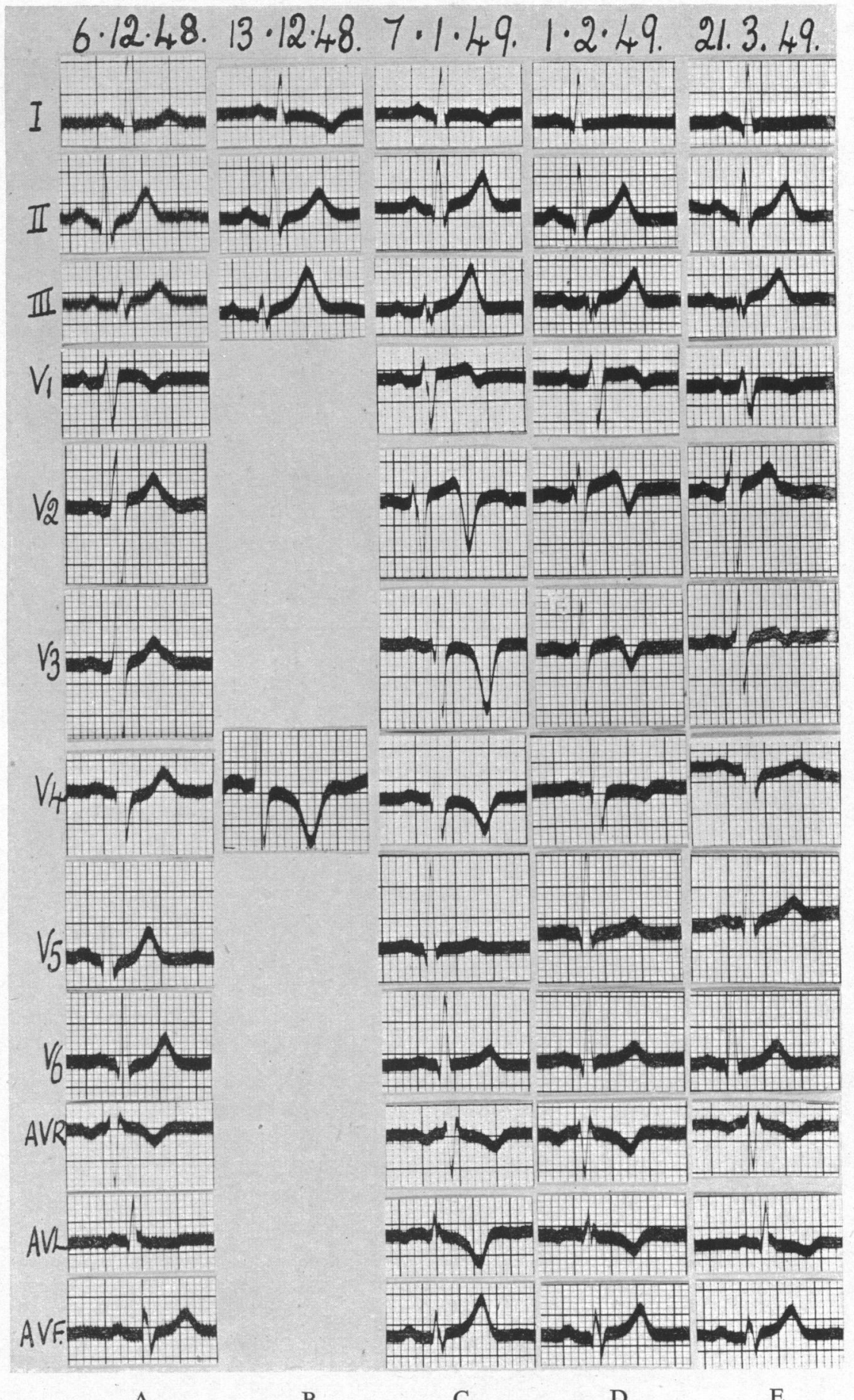

A

B

C

D

E

Fig. 1.-Case 1. Man, aged 52. Four years angina of effort. Coronary attack 4 days previously followed by frequent angina at rest. No pyrexia, normal E.S.R., insignificant fall of B.P. Still occasional angina. Records show anteroseptal ischæmia. (A) Normal record 3 days prior to attack. (B) Inversion of T in I with reciprocal elevation in III, deep inversion of $\mathrm{T}$ in V4 with cove-shaped S-T, 4 days after attack. (C) Changes in 12-lead record involve V2-V4 and AVL with reciprocal effect in III and AVF. (D) Gradual disappearance of abnormalities. (E) Restoration to near normal after $3 \frac{1}{2}$ months; note increase of $R$ in V2 and AVL. 


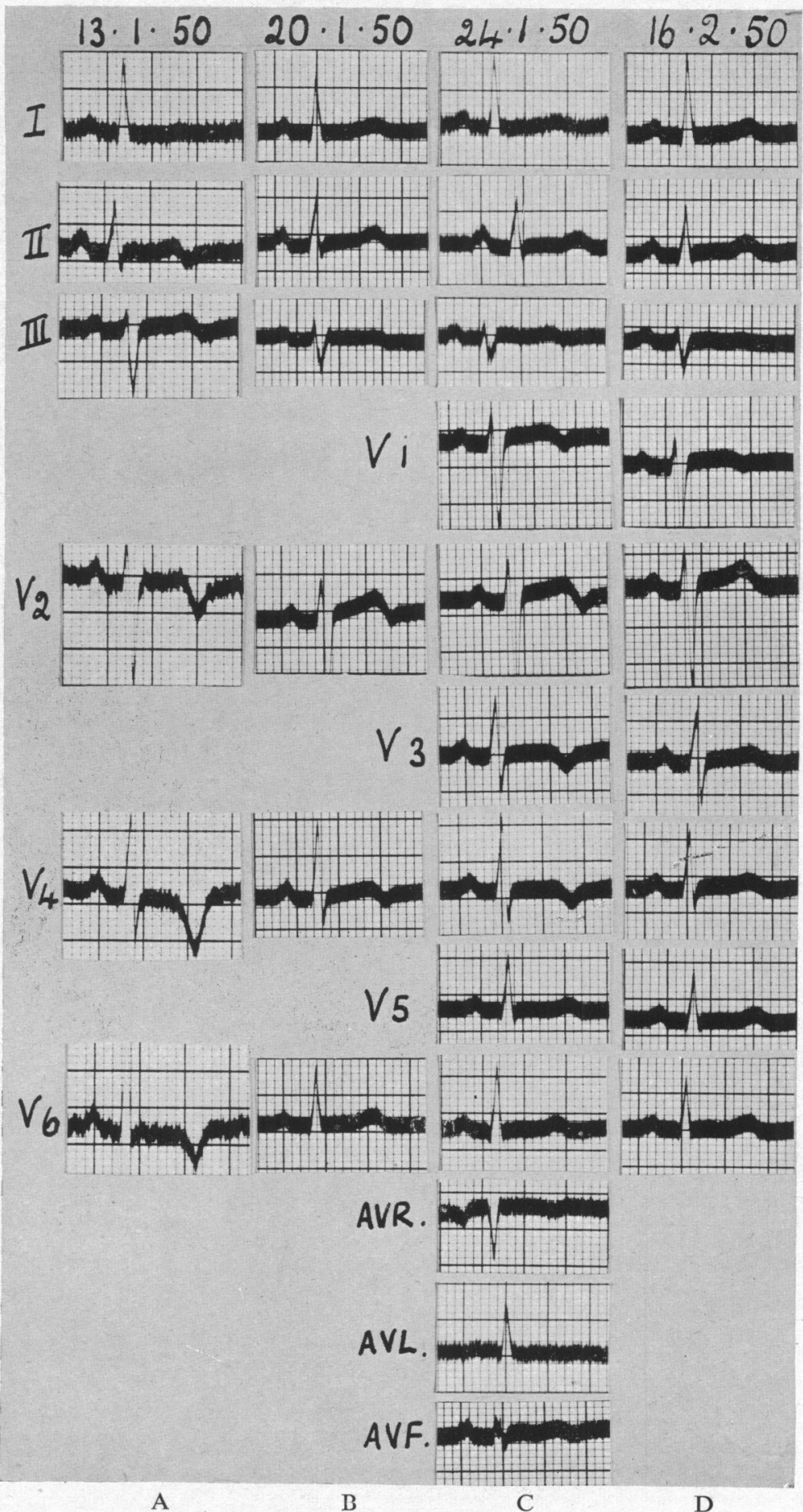

FIG. 2.-Case 2. Woman, aged 56. Coronary attack for $1 \frac{1}{2}$ hours three months previously followed by disabling angina of effort. Rest for 4 weeks then gradual resumption of work. Records show anteroseptal ischæmia. (A) Little change in limb leads, deep T inversion V2-V6, cove-shaped S-T in V4. (B) Considerable improvement after one week's rest. (C) Changes involve V1-V4 in 12-lead record. (D) Normal record after one month. 


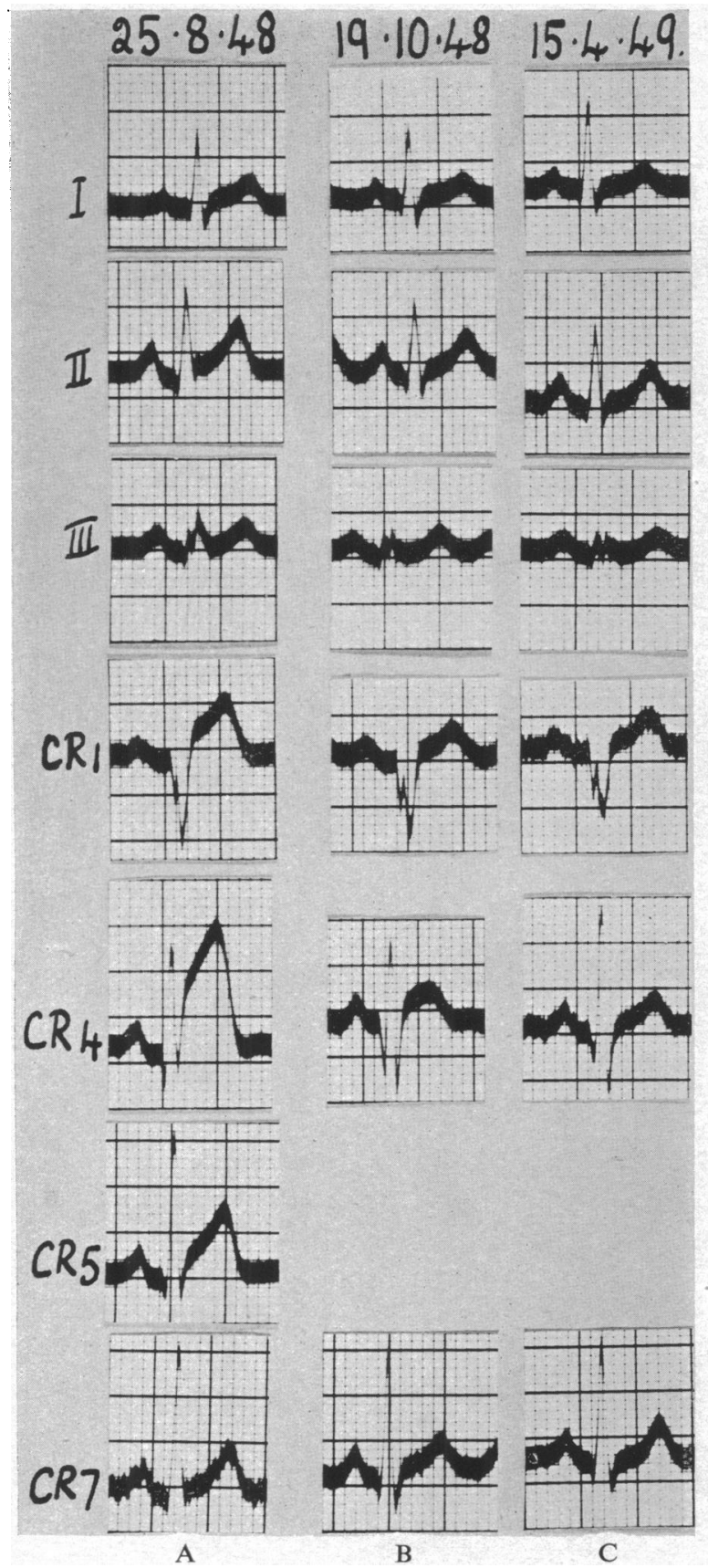

Fig. 3.-Case 3. Man, aged 42. Prolonged anginal pain 6 and 3 days previously, followed by slight pyrexia. Resumed work after 3 week's rest. No further pain. Records show acute anteroseptal ischæmia. (A) S-T elevation of $2 \mathrm{~mm}$. in II, of $4 \mathrm{~mm}$. in CR1, of $6 \mathrm{~mm}$. in CR4, with current of injury. (B) $Q$ wave of $4 \mathrm{~mm}$. with monophasic $T$ still seen in CR4. (C) Normal record except for W complex in CR1, 8 months later.

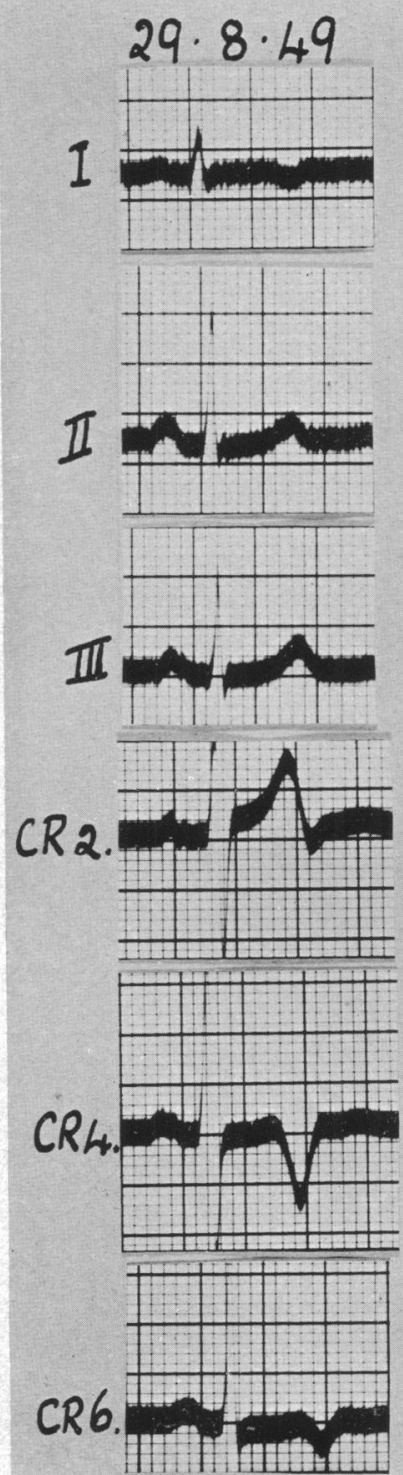

A
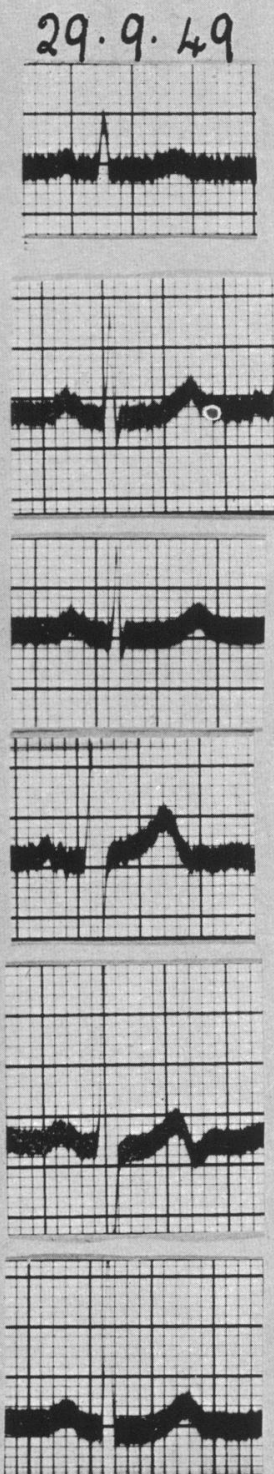

B

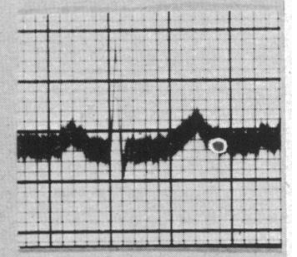

Fig. 4.-Case 4. Man, aged 62. Two months angina of effort. One week previously pain persisted after exertion for $\frac{1}{2}$ hour. Rest for 3 weeks, no further angina. Records show anterolateral ischæmia. (A) Slight $T$ inversion in I, deep $T$ inversion in CR4 and CR6. (B) Normal record after one month. 


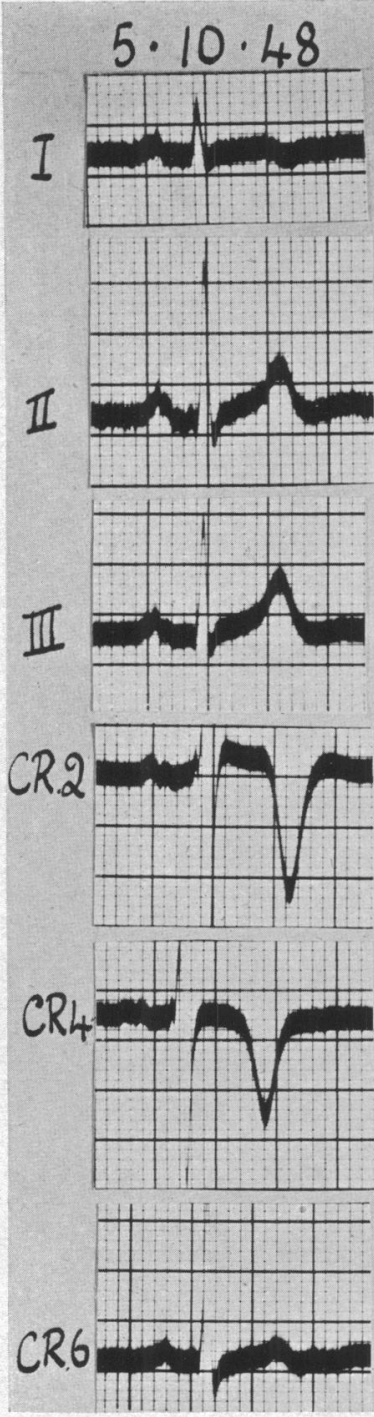

A

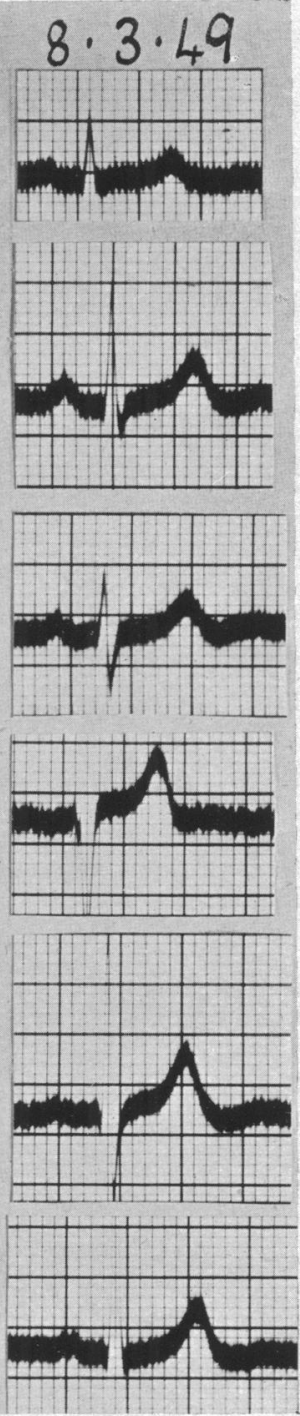

B

Fig. 5.-Case 5. Man, aged 49. Four months angina of effort. Coronary attack for 2 hours 5 days previously ; angina of effort worse since. Rested for 8 weeks ; still occasional angina. Records show anteroseptal ischæmia. (A) Slight $T$ inversion in I with some coving of $S-T$, T inversion of $13 \mathrm{~mm}$. in CR2 with S-T elevation of $2 \frac{1}{2} \mathrm{~mm}$.; similar changes in CR4. (B) Normal record after 5 months.

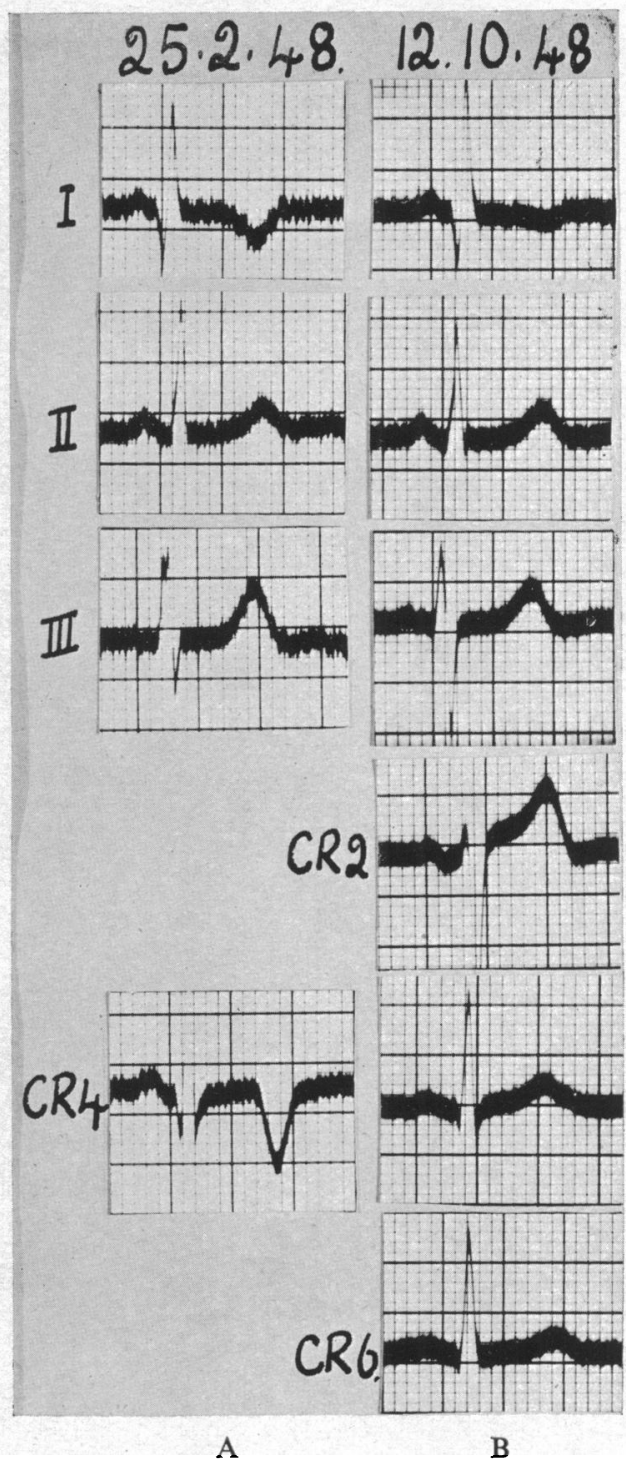

Fig. 6-Case 6. Man, aged 47. Hypertension and occasional angina of effort. Coronary attack started while cranking cab, lasted for 36 hours. No pyrexia or fall of blood pressure. Cardiogram the same evening inconclusive. Records show antero-apical ischæmia. (A) $Q$ wave of $5 \mathrm{~mm}$. and $T$ inversion in I with reciprocal effect in III, small $Q$ in CR4 with T inversion of $7 \mathrm{~mm}$. after 6 weeks. (B) Chest leads normal, slight $T$ inversion and persistent $Q$ wave in I, after 8 months.

small or absent in three records, all showing anteroseptal ischæmia ; pathological Q waves were encountered in seven instances, of these three were of anteroseptal, one of anterolateral, one of antero-apical, and two of posterior pattern. Complete restoration to normal of the electrocardiogram was seen in 14 instances (Fig 2, 4, 5, 8, 9, 10 and 11), and far reaching electrocardiographic 


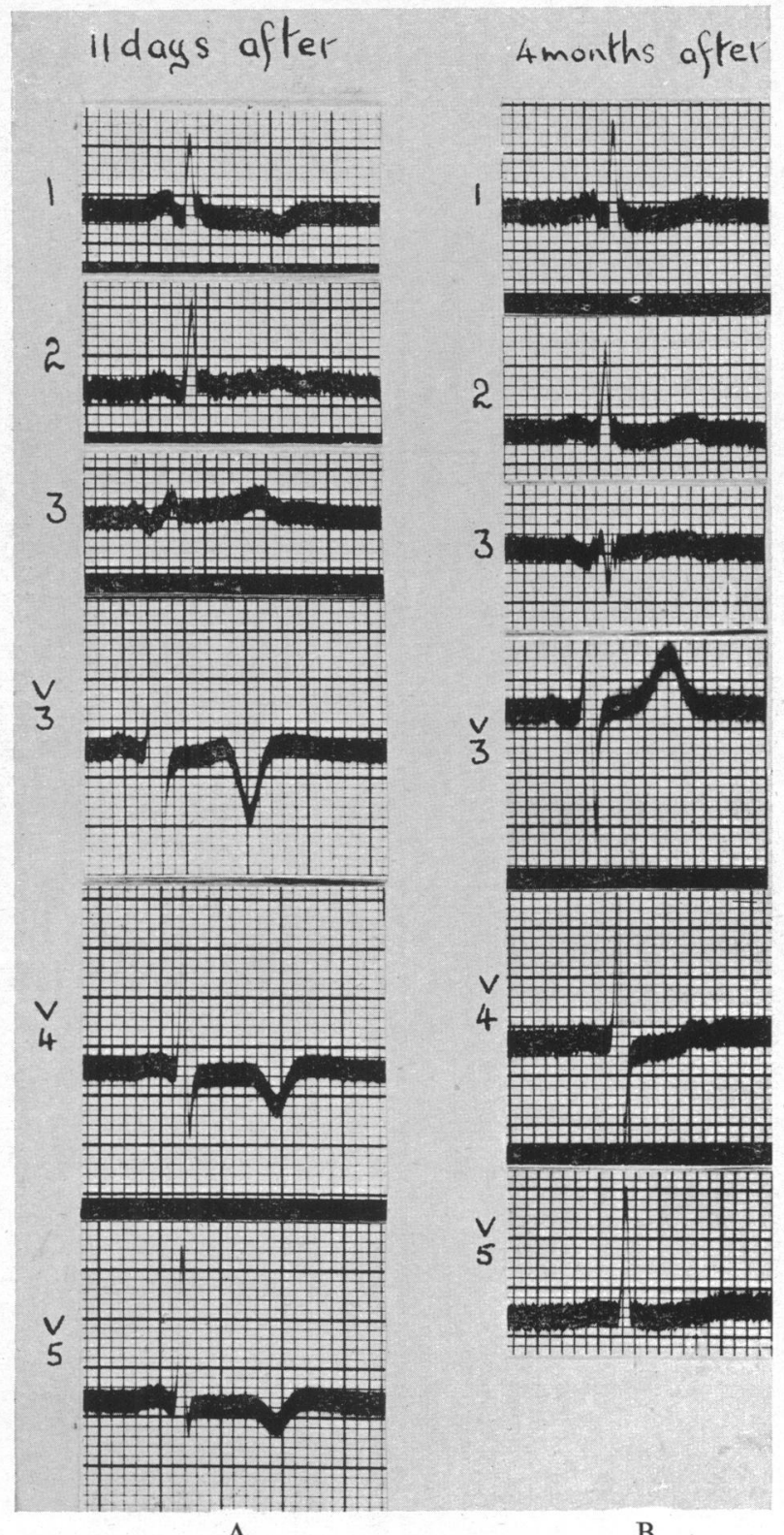

A

B FIG. 7.- Case 7. Man, aged 71. Angina of effort for 3 months, prolonged bouts of pain 14 and 11 days previously,
with vomiting and sweating, requiring morphia. No pyrexia, normal E.S.R., some fall of B.P. Resumed work after 5 weeks ; no pain for 15 months. Occasional angina of effort now. Records show anteroseptal ischæmia. (A) Changes similar to Fig 4 and 5. (B) Record restored almost to normal.

recovery in another 14 (Fig 1, 3,6,7 and 12). Thus, in only 6 of the 35 cases did the abnormal electrocardiogram persist, while in one patient with a posterolateral pattern subsequent changes pointed to an extension of the lesion. The increase or reappearance of a small or absent $R$ was seen 


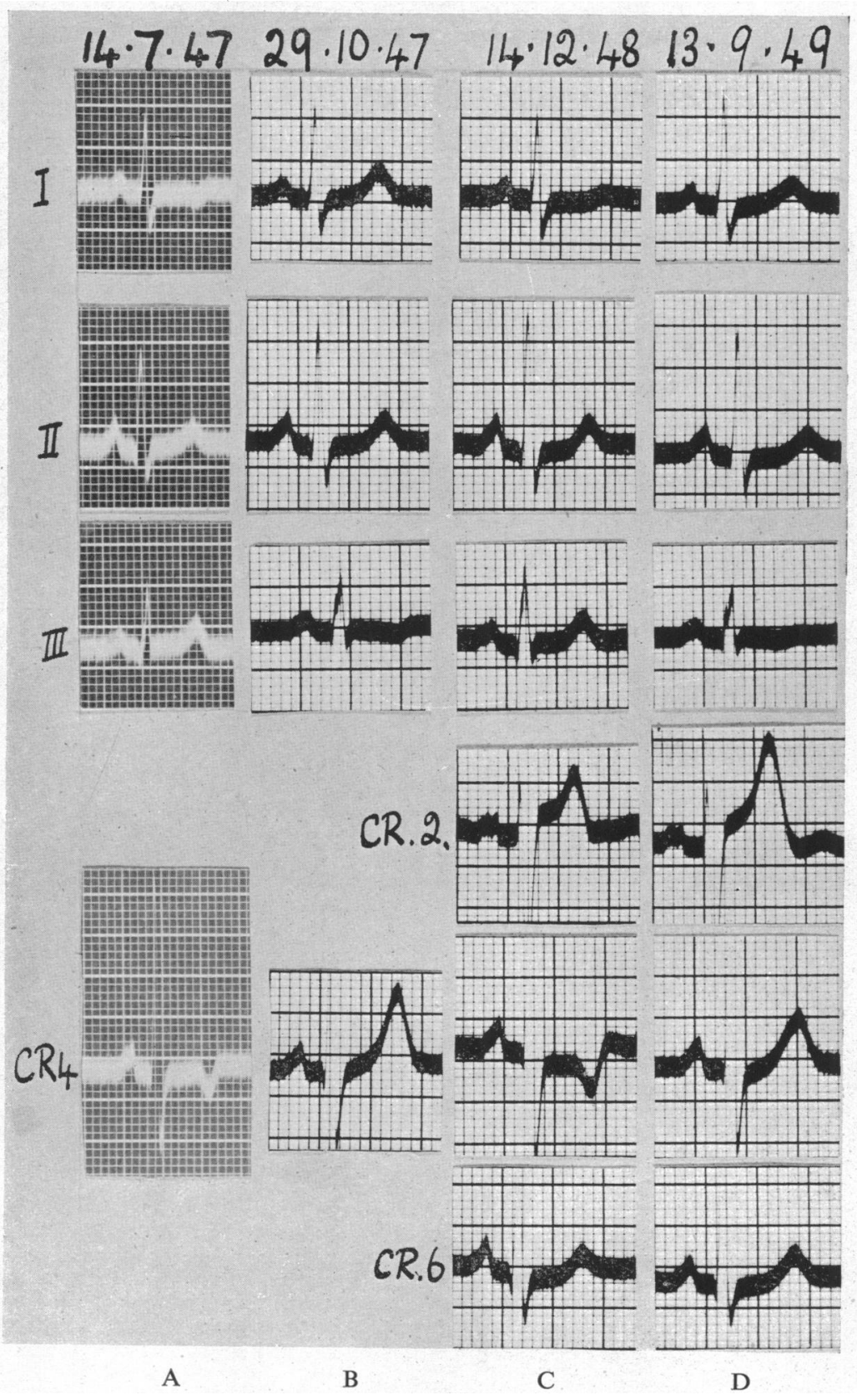

FIG. 8.-Case 8. Man, aged 48. Hypertension and angina of effort for two years. The night previously coronary attack for $1 \frac{1}{2}$ hours requiring morphia. Periods of frequent angina at rest and on effort during the following two years of observation. Never showed pyrexia or fall of blood pressure. Records show antero-apical ischæmia twice reverting to normal. (A) and (C) isolated inversion of T in CR4 with lesser changes in lead I. (B) and (D) normal records 3 and 9 months after (A) and (C).

three times (Fig 1 and 3) and one of these records, the only one with a current of injury, reverted almost to normal (Fig. 3). A pathological $Q$ wave became a permanent abnormality even when other signs of myocardial injury had disappeared (Fig. 6). The time of restoration was difficult to 


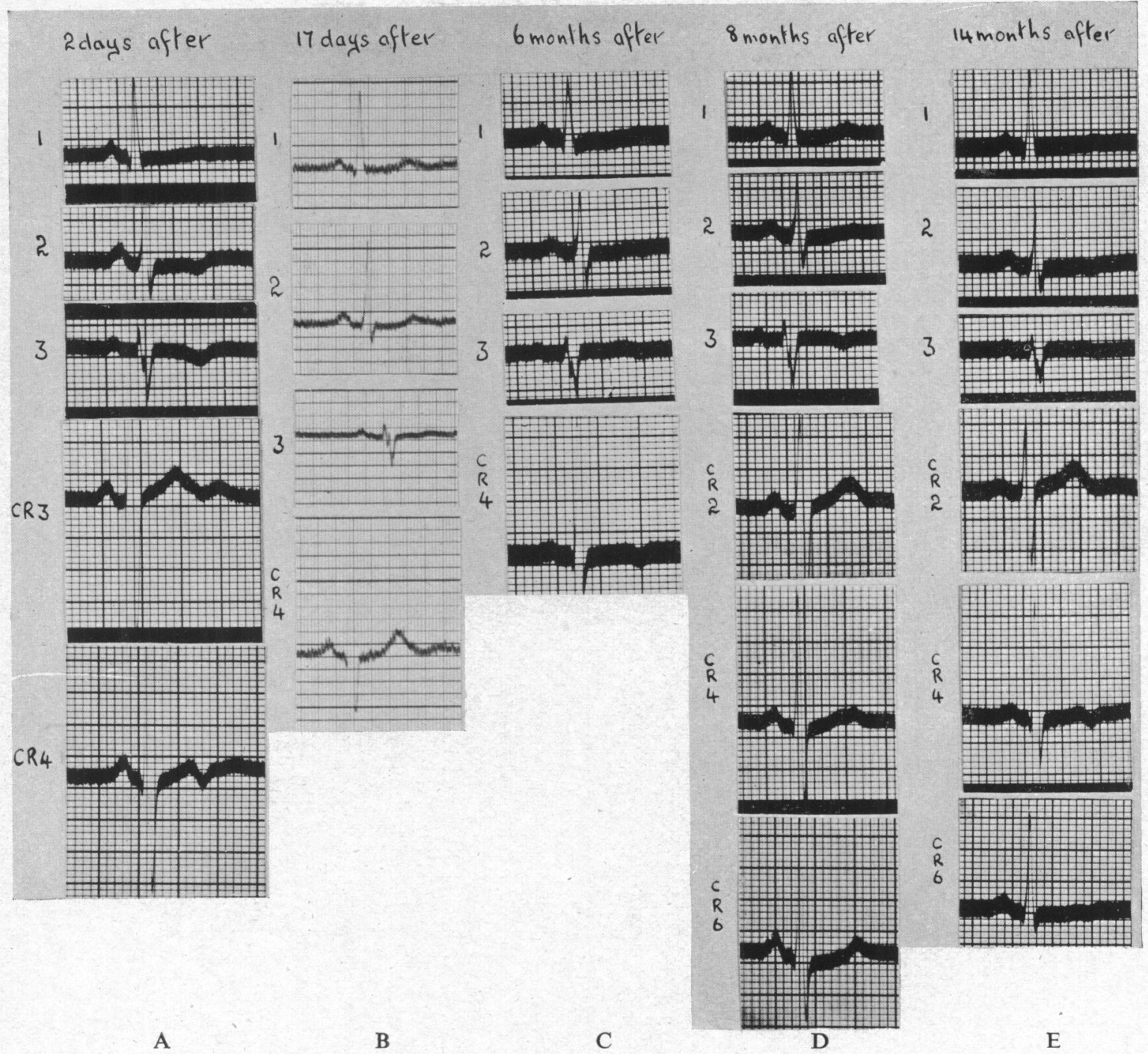

FIG. 9.-Case 9. Man, aged 57. Slight hypertension, obesity ; chain-smoker. Nov. 1947, coronary attack while dancing after heavy meal, with ectopic tachycardia and B.P. 190/135, requiring repeated injections of morphia. No pyrexia. Temporary fall of B.P. No further pain for 7 months. June 1948, frequent angina of effort and at rest. July 1948, cerebral embolus, complete recovery. Attacks now very occasional, and related to mental stress. Records show posterolateral ischæmia with intermittent reversion to normal, unrelated to clinical state. (A), (C) and (E) slight changes in all leads except CR2. (B) and (D) almost normal records.

assess, since records were taken at irregular intervals. A normal record was obtained within a fortnight in Cases 9 and 16, within three and four weeks in Cases 2 (Fig. 2) and 18 ; within five weeks in Case 4 (Fig. 4) ; within three months in Case 1 (Fig. 1), and from six months to two years in the remaining patients (Table III). The electrocardiogram of Case 9 with a posterolateral pattern varied between normal and abnormal when recorded at intervals during the following 14 months and that of Case 8 behaved similarly (Fig. 8 and 9). These changes were apparently independent of the clinical state of the patients ; normal records were sometimes obtained during periods of frequent anginal attacks and vice versa. 
TABLE III

Time of Restoration of Cardiogram in 14 Cases

\begin{tabular}{c|c|c|c|c|c|c|c}
\hline $\begin{array}{c}\text { Less than } \\
\text { 2 weeks }\end{array}$ & $\begin{array}{c}2-5 \\
\text { w. }\end{array}$ & $\begin{array}{c}6-9 \\
\text { w. }\end{array}$ & $\begin{array}{c}10-13 \\
\text { w. }\end{array}$ & $\begin{array}{c}14-26 \\
\text { w. }\end{array}$ & $\begin{array}{c}27-36 \\
\text { w. }\end{array}$ & $\begin{array}{c}37-52 \\
\text { w. }\end{array}$ & $\begin{array}{c}\text { More than } \\
52 \text { w. }\end{array}$ \\
\hline 2 & 2 & 1 & 1 & 3 & 1 & 2 & 2 \\
\hline
\end{tabular}

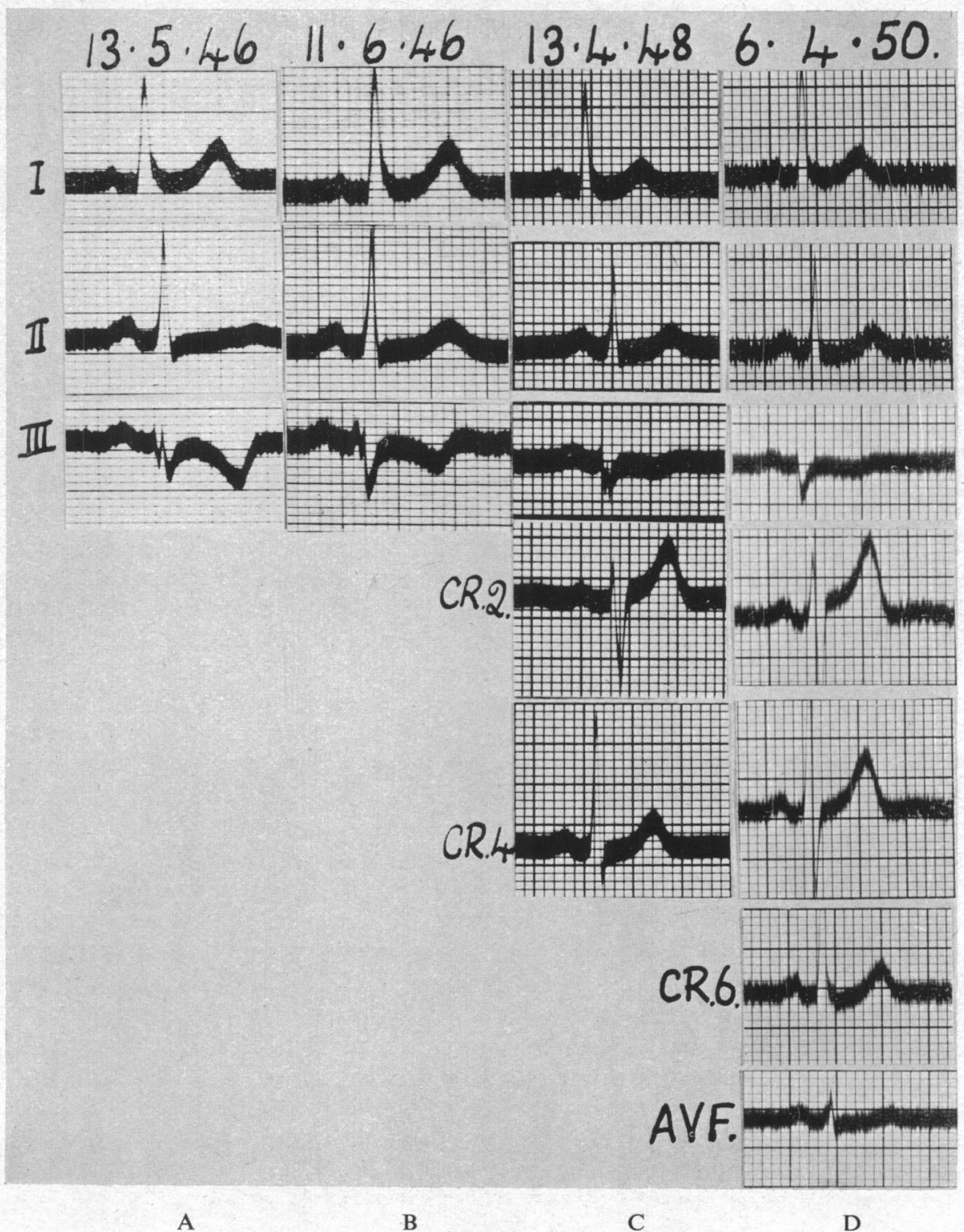

Fig. 10.-Case 10. Man, aged 50. Obese. Angina of effort for two weeks ; attack never prolonged. Rest for two weeks then resumption of activity. No symptoms for $3 \frac{1}{2}$ years. Lately very occasional angina of effort. Records show posterior ischæmia. (A) Flat T in II, small $Q$ and coronary $T$ in III. (B) $T$ upright in II, lesser changes in III. (C) and (D) Normal records 2 and nearly 4 years later. 


\section{Discussion}

East and Oram (1948) out of a material of 367 cases with records diagnostic of cardiac infarction collected 28 showing a recovery of the $T$ waves to normal. The study of the clinical history of these patients failed to give any indication suggesting the temporary nature of the electrocardiographic abnormality and the laboratory data available did not permit any conclusion regarding the severity of the attack. The prognosis in their cases was, however, good and in an average time of four years of observation-7 patients were observed for more than 8 years-only three died and one of these of septicæmia. They also emphasized the frequency of anterior ischæmia, but most of their electrocardiograms antedate serial chest lead recordings and these

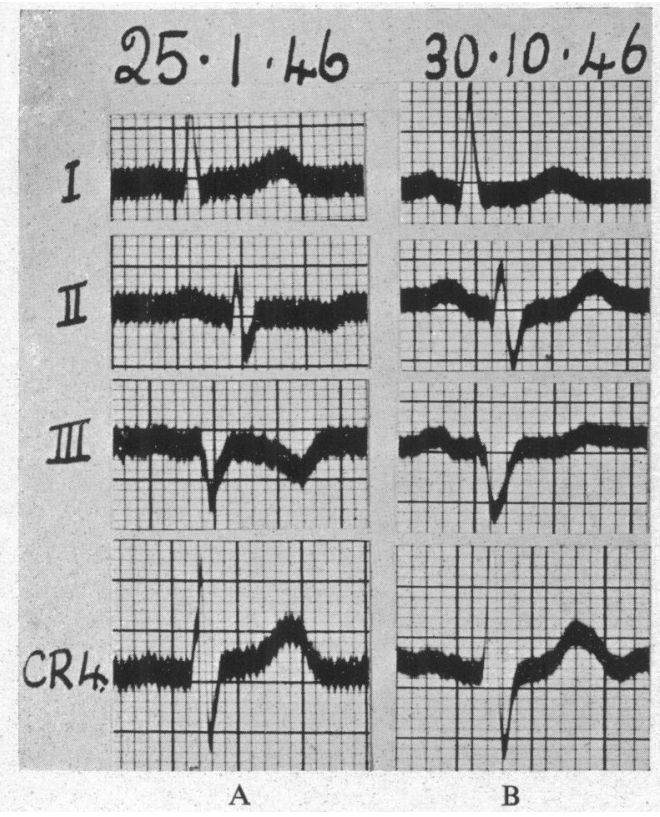

FIG. 11.-Case 11. Man, aged 60. Diabetic. Coronary attack for $1 \frac{1}{2}$ hours after heavy meal ; further pain one and two weeks later. Rest for 4 weeks ; No pyrexia ; W.B.C.'s normal ; slight fall of B.P. No symptoms during one year of observation. Records show posterior ischæmia. (A) Similar to Fig. 10(A). (B) Normal record 9 months later.

for death ; of the remaining 16, in 12 the infarct was well healed, while in 4 it was more recent. Death ensued following a new extensive infarction in another coronary district or from such diverse conditions as cerebral hæmorrhage, bronchopneumonia, uræmia, renal abscess, intestinal obstruction, and peritonitis. Myers, Klein, and Hiratzka (1949) among their posterolateral infarctions, published two further cases with electrocardiograms similar to our anteroseptal pattern. One, in whom a posterolateral infarction coexisted, died of mesenteric thrombosis, the other of a recent posterolateral infarction. Post-mortem examination confirmed in both the existence of patchy subendocardial infarction in the anteroseptal wall of the left ventricle, recent in the first and healed in the second.

Myocardial recovery depends on the balance between rate of arterial narrowing and development of vascular anastomoses. Blumgart, Zoll, Freedberg, and Gilligan (1950) found only fifteen per cent of normal human hearts with interarterial communications of $\mathbf{4 0}$ micron diameter or more. 
The septum, however, seems to be an exception. Laubry, Soulié, and Thys (1948) found septal anastomoses in 4 out of 5 healthy hearts in young people under 30, and in 16 among 29 healthy hearts in those between 40 and 70 . Over 70 they tend to disappear and were found only in 4 out of 14. While in hearts without coronary disease these anastomotic channels were small, in hearts with infarcts or coronary obstruction they were almost as large as the normal perforant arteries of the septum. Thereby new circulatory conditions were created to help myocardial recovery. There

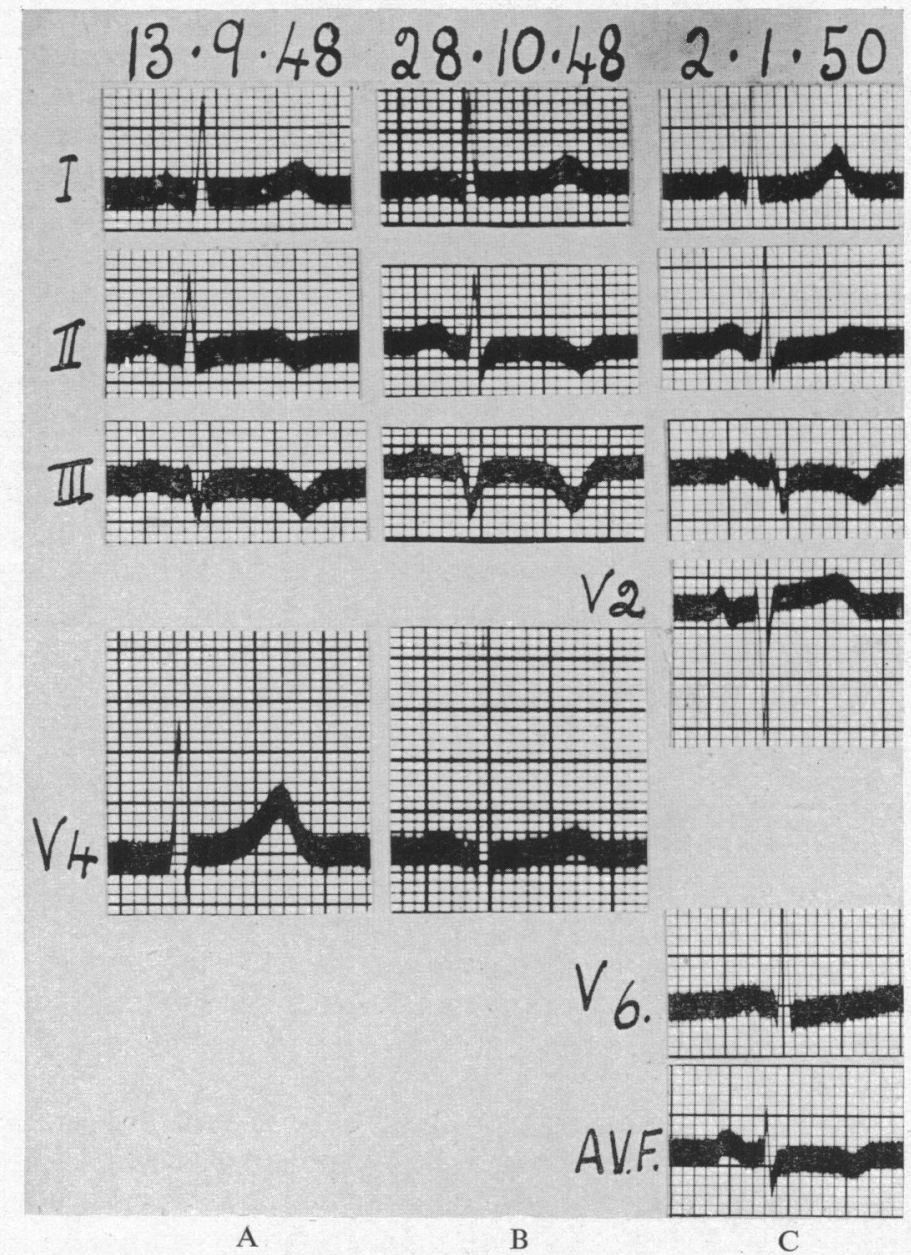

Fig. 12.-Case 12. Man, aged 73. Coronary attack 12 days previously for 2 hours ; disabling angina of effort since. Rest for a fortnight then resumed work. No pain now for 20 months. Records show posterior ischæmia. (A) Similar to Fig. 10(A) and 11(A). (B) No change $1 \frac{1}{2}$ months later. (C) Only partial restoration after more than one year.

is thus agreement between the French and American authors that gradually developing arteriosclerosis of the larger coronary arteries is a strong stimulus for the development of collateral circulation in the heart (Blumgart et al, 1950) and this applies not only to the septum but to other myocardial regions. Such a well developed anastomotic circulation may prevent myocardial infarction even in the presence of multiple coronary occlusion (Ravin and Geever, 1946). From the fact that seventeen of our series had angina before the coronary attack and a further six developed it following this, it may be presumed that in two-thirds of our series such a narrowing of the coronary arteries existed. 


\section{TREATMENT}

There was far-reaching agreement between the clinical and the electrocardiographic features in our series, in so far as both were slight. Profound changes of the ventricular complex such as are seen in through and through infarction and endocardial involvement were absent ; thus there seemed to be no risk of mural thrombus formation. There was no shock with dangerous fall of blood pressure, and further extension of infarction therefore seemed unlikely. Consequently it was decided not to employ anticoagulant therapy but to adopt the simplest form of treatment consisting of rest in bed and sedatives. Rest in bed in 7 out of 9 patients seen in general practice was reduced to a fortnight. Although these patients were allowed to sit up in bed and to use the commode after the second day the result in these was as good as in the others who were kept in bed for from 3 to 5 weeks, and the proportion without angina after the attack even greater (Papp, 1949). This is in agreement with the results of Freedberg et al. (1948) in their cases with coronary failure and does not bear out the objections of Blumgart et al. (1950) against shortening the period of rest in bed on the ground of their experimental results. Absolute rest for these patients was regarded as not only an unnecessary hardship but as a disadvantage and they were encouraged to move in bed, to adopt the most comfortable position, to do respiratory exercises and to move the legs to avoid venous thrombosis. In addition to sedatives (phenobarbitone $\frac{1}{2}$ grain, or sodium amytal 2 grains, twice daily) the following drugs were used with the aim of preventing recurring angina and with varying success : aminophyllin 3 grains thrice daily, papaverine $1 \frac{1}{2}$ grains thrice daily, the latter often combined with atropine sulphate $1 / 150$ of a grain. In addition, trinitrin 1/100 of a grain was given as a routine several times a day. For the suppression of the attacks double doses of trinitrin (1/50 of a grain) were given; if this was ineffective pethidine $100 \mathrm{mg}$. was injected intramuscularly. The effect of pethidine in these slight but often prolonged coronary attacks was better than that of morphine. It acts more quickly, has no exciting effect, and produces rapid sleep which lasts from half to one hour. Owing to the danger of addiction this drug should be used with caution.

All the patients recovered from their acute attack and were able to resume their occupations. We do not think that the cerebral thrombosis eight months after the acute attack in Case 9 or the cardiac failure in Case 15 could have been avoided by anticoagulant treatment. Extension of infarction, though not seen in our slight anteroseptal cases, was described by Rosenbaum, Wilson, and Johnston (1945), but we doubt whether these exceptions justify the use of anticoagulants in similar patients. Our Case 22 with a posterolateral pattern, the only one among 33 in whom the cardiogram showed further extension, made a good recovery and never gave the clinical impression of being seriously ill.

The period of observation of our cases is too short to be of prognostic value, but the fact that two of our patients over 70 years of age who had their acute attacks 15 and 19 months ago are well and active, justifies an optimistic outlook. Although we have not experienced them, fatalities may occur in slight coronary attacks (East and Oram, 1948) presumably through ventricular fibrillation (ectopic tachycardia was seen during the attack twice in our series). The risk of further severe attacks after months or years is as real in slight as in extensive myocardial infarction, but this cannot be prevented by any available treatment during the acute attack.

\section{SUMMARY}

Out of a material of 109 consecutive cases diagnosed as cardiac infarction, comprising hospital in-patients, patients seen in consultant and in general practice, 33 (little less than one-third) had slight coronary attacks. Shock and cardiac failure were not found in them, the blood pressure never fell to dangerous levels, clinical and laboratory signs of myocardial necrosis were slight or absent, and all the patients made uncomplicated recoveries. The ages of these patients varied between 42 and 73, two being over 70. The proportion of men to women was three to one. 
Electrocardiograms recorded in 35 attacks (two patients had two attacks and both slight) showed the following patterns of myocardial ischæmia : anteroseptal 17, anterolateral 7, anteroa-pical 2, posterior 6, posterolateral 3. Changes in S-T and T patterns were prominent in all ; diminution or absence of $R$ was encountered in 3 and pathological $Q$ waves in 7 instances. Complete restoration to normal or far reaching electrocardiographic recovery was almost the rule and resulted in 28 instances. Anteroseptal patterns showed the greatest rate of restoration and 16 out of 17 became normal or nearly so, and so did 5 out of 7 anterolateral, and 5 out of 6 posterior patterns. Recovery took place within two months in 5 patients and from 4 to 16 months in the remaining 23 . In 6 , the electrocardiogram remained unchanged and only one posterolateral pattern showed further extension of infarction.

These electrocardiographic patterns are suggestive of small intramural or patchy subepicardial infarctions and as such they are in close agreement with the slight clinical symptoms. The notable frequency of cardiographic restoration suggests good collateral circulation in the infarcted areas, stimulated perhaps by pre-existent arterial narrowing (more than half of these patients had long standing angina and two-thirds continued having it after the infarction).

Anticoagulant treatment is not indicated since the risk of thrombo-embolic complications or extension of infarction is so slight. Further thrombosis in major coronary branches must remain an ever existing danger.

We are indebted to the Physicians of the Charing Cross Hospital for permission to use certain of their cases, and to Miss Anne Smith, cardiographic technician to the hospital, for electrocardiography of many cases and for the mounting.

\section{REFERENCES}

Blumgart, H. L., Zoll, P. M., Freedberg, A. S., and Gilligan, D. R. (1950). Circulation 1, 11.

Brock, R. C., and Campbell, M. (1950). Brit. Heart J., 12, 420.

East, T., and Oram, S. (1948). Ibid. 10, 263.

Freedberg, A. S., Blumgart, A. L., Zoll, P. M., and Schlesinger, M. J. (1948) J. Amer. med. Ass., $138,107$.

Laubry, C., and Soulié, P. (1950). Les Maladies des Coronaires, Second ed., Paris.

- , and Thys, H. (1948). Arch. Mal. Coeur., 41, 1.

Master, A. M. (1946). New York Med., 2, No. 9, 19.

Myers, G. B., Klein, H. A., and Stofer, B. E. (1948). Amer. Heart J., 36, 525

-, , and Hiratzka, T. (1949). Ibid., 38, 837

Papp, C. (1949). Brit. Heart J., 11, 411.

Ravin, A., and Geever, E. F. (1946). Arch. intern. Med., 78, 125.

Rosenbaum, F. F., Wilson, F. N., and Johnston, F. D. (1945). Amer. Heart J., 30, 11. 